\title{
The Value of Urine Soluble Triggering Receptor Expressed on Myloid Cell-1 in Early Diagnosis of Sepsis Associated Acute Kidney Injury
}

\author{
Mohamed A. Elbaz, Effat H. Assar, Heba M. Sarhan, Ayat I. Fattouh
}

\begin{abstract}
Department of pediatrics, Benha faculty of medicine, Benha University, Egypt.

Correspondence to: Ayat I.

Fattouh, Department of pediatrics, Benha faculty of medicine, Banha University, Egypt.

Email:

khaber38@yahoo.com
\end{abstract}

Received: 5 January 2021

Accepted: 11 March 2021

\section{Abstract:}

Introduction: Sepsis is a main cause of admission to PICU \& NICU. Because of its rapid progression, the disease may (within a relatively short period) lead to a multiple organ dysfunction syndrome (MODS). Despite recent advances in the comprehensive management of the patients, sepsis is still a life-threatening condition with a poor outcome. Early diagnosis of sepsis plays a significant role; for each hour of delay of appropriate therapy, the mortality increases by $7.6 \%$. We explored the diagnostic value of a urine soluble triggering receptor expressed on myeloid cells-1 (sTREM-1) for early identification of sepsis, and the secondary acute kidney injury (AKI). Methods: This case control study was conducted on 50 critically ill children with sepsis admitted to PICU and 20 healthy children as a control group. The study groups were classified as follows: I. Patients groups: - Group (A): Sepsis patients with AKI - Group (B): Sepsis

patients without AKI. II. Control group: Group (C): with matching age \& sex. Results of urine sTREM-1, CBC, CRP and s. creatinine were recorded on day 1 of admission. Results: There were no significant differences between all the study groups as regards age $\&$ gender. $\mathrm{P}$ values were $0.43 \& 0.709$ respectively. Urine sTREM-1 showed an overall significant difference between the study groups ( $\mathrm{P}$ value $<0.001$ ). Pairwise analysis revealed that the median sTREM-1 was significantly higher in group A (404 pg/ml) compared to group B (189.6 pg/ml) \& C (0). P value was $<0.001$. Also, it was significantly higher in group B $(189.6 \mathrm{pg} / \mathrm{ml})$ compared to group C $(0 \mathrm{pg} / \mathrm{ml})$. Conclusions: Besides being non-invasive, urine sTREM-1 testing is a sensitive parameter for early diagnosis of sepsis. It can also provide an early warning of possible secondary AKI in sepsis patients.

Keywords: urine soluble triggering receptor expressed on myeloid cells-1(sTREM-1), sepsis, prognosis, acute kidney injury (AKI). 



\section{Introduction:}

Sepsis is a main cause of admission to PICU\&NICU. Because of its rapid progression, the disease may, within a relatively short period, lead to secondary multiple organ dysfunction syndrome (MODS). Despite recent advances in the comprehensive management of the patients, sepsis is still a life-threatening condition with a poor outcome. Early diagnosis of sepsis plays a significant role; for each hour of delay of appropriate therapy, the mortality increases by $7.6 \%$.

Acute kidney injury is a well-known health problem associated with longer length of stay, morbidity, and mortality in adults. Sepsis related AKI occurs in about $19 \%$ of sepsis patients, and may reach $23 \%$ among septic shock patients, showing a mortality rate of $70 \%$. Therefore, it is clinically important to identify indicators that can be used for early diagnosis and prognosis of sepsis and the induced AKI. (1)

The current gold-standard clinical and biochemical criteria for the diagnosis of AKI are the Risk Injury Failure Loss End-stage renal disease (RIFLE) and its modification. Acute Kidney Injury Network (AKIN) criteria rely on the urine output and serum creatinine which are insensitive, nonspecific, and late markers of the disease. Serum creatinine is considered an inferior marker of kidney function during critical illness, as the rise in serum creatinine is commonly delayed after kidney function declines by $50 \%$. (2)

Triggering receptor expressed on myeloid cells-1 (TREM-1) is considered an immunoglobulin expressed on the cell membrane of neutrophils, monocytes, and macrophages. TREM-1 belongs to a family related to the natural killer cell receptors. TREM-1 up-regulates the expression levels of pro-inflammatory chemokines and cytokines and amplifies the inflammatory responses mediated by Toll-like receptors. Urinary soluble triggering receptor that is expressed on myeloid cells-1 (sTREM-1) is a form of TREM-1 that may be released into urine upon the up-regulated expression of TREM-1. This soluble form can be measured in all biological fluids and may be used as a diagnostic biomarker for evaluating the severity and prognosis of sepsis (3).

In clinical studies involving patients with severe sepsis, sTREM-1 has shown the potential to provide an excellent predictive value for septic shock/death. For instance, the sTREM-1 level was found to be associated significantly with AKI, and may be used as a diagnostic and prognostic 
biomarker for AKI in critically ill patients with sepsis (4).

\section{Purpose:}

Evaluating the role of sTREM-1 as an early predictor for sepsis-related acute kidney injury in patients admitted to intensive care units.

\section{Patients and methods:}

\section{Patients:}

This case control study was conducted on 50 critically ill children with sepsis who were admitted to the PICUs of Benha University Hospital and Benha Children Hospital and 20 healthy children as a control group.

This study was done from July 2019 to Dec 2019 and was approved by the Ethical Committee of Benha Faculty of Medicine.

Study groups (patients and control) were classified as follows:

I. Patients groups:

- Group (A): Sepsis patients with AKI (25 patients).

- Group (B): Sepsis patients without AKI (25 patients).

II. Control group: Group (C): with matching age $\&$ sex (20 patients).

\section{Ethical Consideration:}

- Verbal consents were taken from the parents of the children before enrollment in our research.

- We took the permission from the administrations of both Benha University and Benha Children Hospital to carry out our study.

\section{Inclusion Criteria:}

All patients aged 2 months to 16 years of both sexes who are admitted to PICU with the criteria of sepsis and severe sepsis/septic shock according to the American College of Chest Physicians/Society of Critical Care Medicine Consensus Conference i.e. patients with two or more of the following:

(1) Temperature more than $38^{\circ} \mathrm{C}\left(100.4^{\circ} \mathrm{F}\right)$ or less than $36^{\circ} \mathrm{C}\left(96.8^{\circ} \mathrm{F}\right)$.

(2) Heart rate more than standard for age.

(3) Respiratory rate more than standard for age or $\mathrm{PaCO} 2$ less than $32 \mathrm{mmHg}$.

\section{Exclusion Criteria:}

Any patient who had a history of chronic renal failure or was subjected to renal transplantation.

Methods:

- Full medical history \& clinical examination.

- Investigations:

- Complete Blood Count.

- C-Reactive Protein.

- Serum Creatinine.

- Blood Urea Nitrogen.

- Arterial Blood Gases.

- Urine Analysis.

- Urine sTREM-1 on day 1 of admission. 


\section{- Biomarker assay:}

Urine samples for biomarker analysis by means of immunoassay. Paired urine sample and s. creatinine on day 1 of admission were withdrawn and examined.

Manufacturers name and address: Room212, Meilan building,Shanghai China

\section{Statistical design:}

The collected data will be tabulated and analyzed by suitable statistical methods using SPSS program.

\section{Statistical analysis:}

Data management and statistical analysis were done using SPSS vs.25. (IBM, Armonk, New York, United States of America).

Numerical data were presented as means and standard deviations or medians and ranges.

Categorical data were presented as numbers and percentages.

Ages and sTREM values of three groups were compared using Kruskal Wallis test. Gender distribution was compared using Chi-square test.

Comparisons between group A \& B were done using independent $\mathrm{t}$ test or Mann Whitney $U$ test for normally and nonnormally distributed numerical data respectively. Categorical data were compared using Chi-square test.

Correlation analysis was done between sTREM and other parameters using
Pearson's or Spearman's correlation, " $r$ " is the correlation coefficient. It ranges from -1 to +1 . -1 indicates strong negative correlation. +1 indicates strong positive correlation while 0 indicates no correlation.

ROC analysis was done for sTREM in prediction of sepsis related kidney injury. Area Under Curve (AUC) with 95\%, best cutoff point and diagnostic indices were calculated.

All $\mathrm{P}$ values were two sided. $\mathrm{P}$ values less than 0.05 were considered significant.

\section{Results}

\section{General characteristics:}

There were no significant differences between all groups as regards age $\&$ gender. $\mathrm{P}$ values were $0.43 \& 0.709$ respectively.

\section{(Table 1 \& figure 1)}

\section{Urine sTREM-1 in the study groups:}

Urine sTREM-1 showed an overall significant difference between all the groups (P value <0.001). Pairwise analysis revealed that the median STREM-1 was significantly higher in group A (404 pg/ml) compared t group B (189.6 pg/ml) \& C (0 $\mathrm{pg} / \mathrm{ml})$. $\mathrm{P}$ value was $<0.001$. Also it was significantly higher in group B (189.6 $\mathrm{pg} / \mathrm{ml})$ compared to group C $(0 \mathrm{pg} / \mathrm{ml})$.

(Table 2) 
Length of PICU \& hospital stay:

Median length of PICU stay was significantly higher in group A (14 days) compared to group B (3 days). P value was 0.009 .

The median length of hospital stay was significantly higher in group A (14 days) compared to group B (3 days). $\mathrm{P}$ value was 0.014. (Table 3 \& figure 2)

\section{Anthropometric measures:}

The median weight was significantly higher in group B (14 kg) compared to group A (10 $\mathrm{kg})$. P value was 0.043 .

There were no significant differences between these groups as regards weight percentile, height, height percentile \& BMI.

$\mathrm{P}$ values were $0.968,0.337,0.186 \& 0.422$ respectively. (Table 4)

\section{Laboratory measures:}

The median CRP value was significantly higher in group A (168 mg/L) compared to group B (96 mg/L). P value was 0.002 . There were no significant differences between these groups as regards the TLC, $\mathrm{Hb}$ level and platelet count. $\mathrm{P}$ values were 0.107, 0.057 and 0.365 respectively. (Table

\section{5 \& figure 3)}

Serum creatinine, blood urea nitrogen, UOP \& GFR in day 1of admission:

The mean serum creatinine level was significantly higher in group A (3.172 $\mathrm{mg} / \mathrm{dl})$ compared to group B $(0.8 \mathrm{mg} / \mathrm{dl})$. P value was $<0.001$.

The median blood urea was significantly higher in group A $(94 \mathrm{mg} / \mathrm{dl})$ compared to group B (21 mg/dl) P value was $<0.001$.

The median urine output was significantly lower in group A $(0.5 \mathrm{ml} / \mathrm{d})$ compared to group B $(2.2 \mathrm{ml} / \mathrm{d}) \mathrm{P}$ value was $<0.001$.

The median GFR was significantly lower in group A $(12.5 \mathrm{ml} / \mathrm{min})$ compared to group B (44 ml/min) $\mathrm{P}$ value was $<0.001$. (Table 6 and figures $4 \& 5$ )

\section{Urine analysis in the patients groups:}

Proteinurea was significantly commoner in group A (64\%) compared to group B (8\%). $\mathrm{P}$ value was $<0.001$.

Serum K was significantly higher in group A (6.9 mmol/L) compared to group B (4 $\mathrm{mmol} / \mathrm{L})$. $\mathrm{P}$ value was $<0.001$.

There were no significant differences between the patients groups as regards the frequency of appearance of pus, glucose and acetone in urine. (Table $7 \&$ figure 6)

\section{pRIFLE in group $A$ :}

As regards the pRIFLE, $12 \%$ of the patients showed renal failure and $88 \%$ showed AKI. (Table 8)

\section{Mortality in both groups:}

Mortality was significantly higher in group A $(72 \%)$ compared to group B $(0 \%)$. P value was $<0.001$. (Table 9 \& figure 7) 
Correlation between sTREM-1 \& other parameters in group $\mathrm{A}$ :

There was a significant positive correlation between sTREM-1 \& $\mathrm{K}(\mathrm{r}=0.570$ \& $\mathrm{P}$ value was 0.003$)$.

There were significant negative correlations between sTREM-1 \& weight $(\mathrm{r}=-0.432 \& \mathrm{P}$ value $=0.031)$, height $(\mathrm{r}=-0.551 \& \mathrm{P}$ value $=0.004)$ and BMI $(\mathrm{r}=-0.644 \& \mathrm{P}$ value $=$ 0.001).(Table 10 \& figure 8)

\section{Correlation between sTREM-1 \& other} parameters in group B:

There were no significant correlation between sTREM-1 \& other parameters in group B.

(Table 11)

\section{ROC analysis for STREM-1 in prediction} of sepsis related $\mathrm{AKI}$ :

ROC analysis was done for prediction of sepsis related AKI. ROC analysis showed significant AUC of 0.955 with $95 \%$ confidence interval ranged from 0.907 to 1.0. Best cutoff point was $>280$ at which sensitivity \& specificity were $84 \%$ \& $92 \%$ respectively. $\mathrm{P}$ value was $<0.001$.

(Table 12 \& figure 9)

Table (1): Comparison between the studied groups regarding age and Gender :

\begin{tabular}{|c|c|c|c|c|c|c|}
\hline \multicolumn{3}{|c|}{ Variable } & \multirow{2}{*}{$\begin{array}{c}\begin{array}{c}\text { Group A } \\
(\mathbf{n = 2 5})\end{array} \\
1.4(0.5-14)\end{array}$} & \multirow{2}{*}{$\begin{array}{c}\text { Group B } \\
(\mathbf{n}=\mathbf{2 5})\end{array}$} & \multirow{2}{*}{$\begin{array}{c}\text { Group C } \\
(\mathbf{n}=\mathbf{2 0}) \\
2(0.4-13)\end{array}$} & \multirow{2}{*}{$\frac{\text { P value }}{0.43}$} \\
\hline Age (Years) & Median & ange) & & & & \\
\hline \multirow[t]{2}{*}{ Gender } & Males & $\mathrm{n}(\%)$ & $21(84.0)$ & $19(76.0)$ & $15(75.0)$ & \multirow{2}{*}{0.709} \\
\hline & Females & $\mathrm{n}(\%)$ & $4(16.0)$ & $6(24.0)$ & $5(25.0)$ & \\
\hline
\end{tabular}

Kruskal Wallis test was used for age. Chi-square test was used for gender.

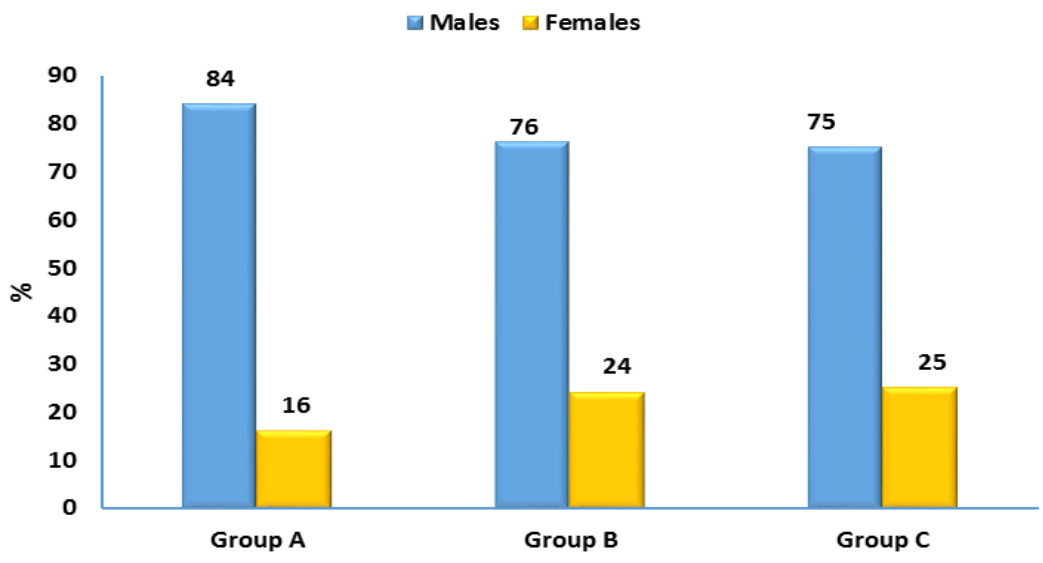

Figure (1): Sex distribution in the study groups 
Table (2) : sTREM-1 in study groups :

\begin{tabular}{|c|c|c|c|c|c|}
\hline & able & $\begin{array}{c}\text { Group A } \\
(\mathbf{n}=\mathbf{2 5})\end{array}$ & $\begin{array}{c}\text { Group B } \\
(\mathbf{n}=\mathbf{2 5})\end{array}$ & $\begin{array}{c}\text { Group C } \\
(\mathbf{n}=\mathbf{2 0})\end{array}$ & $P$ value \\
\hline $\begin{array}{c}\text { sTREM-1 } \\
(\mathrm{pg} / \mathrm{ml})\end{array}$ & Median (range) & $404(201-510)^{\mathrm{a}}$ & $189.6(150-310)^{b}$ & $0(0-5)^{\mathrm{c}}$ & $<0.001$ \\
\hline
\end{tabular}

Kruskal Wallis test was used. Pairwise analysis was done \& different letters indicate significant pair. Pairwise comparisons were Bonferroni adjusted.

Table (3) : Length of PICU and hospital stay (Days) in patient groups :

\begin{tabular}{lcccc}
\hline \multicolumn{1}{c}{ Variable } & $\begin{array}{c}\text { Group A } \\
(\mathbf{n}=\mathbf{2 5})\end{array}$ & $\begin{array}{c}\text { Group B } \\
(\mathbf{n}=\mathbf{2 5})\end{array}$ & P value \\
\hline $\begin{array}{l}\text { Length in PICU stay(days) } \\
\begin{array}{l}\text { Length in hospital } \\
\text { stay(days) }\end{array}\end{array}$ & Median (range) & $14(3-24)$ & $3(3-22)$ & 0.009 \\
\hline
\end{tabular}

Mann Whitney U test was used

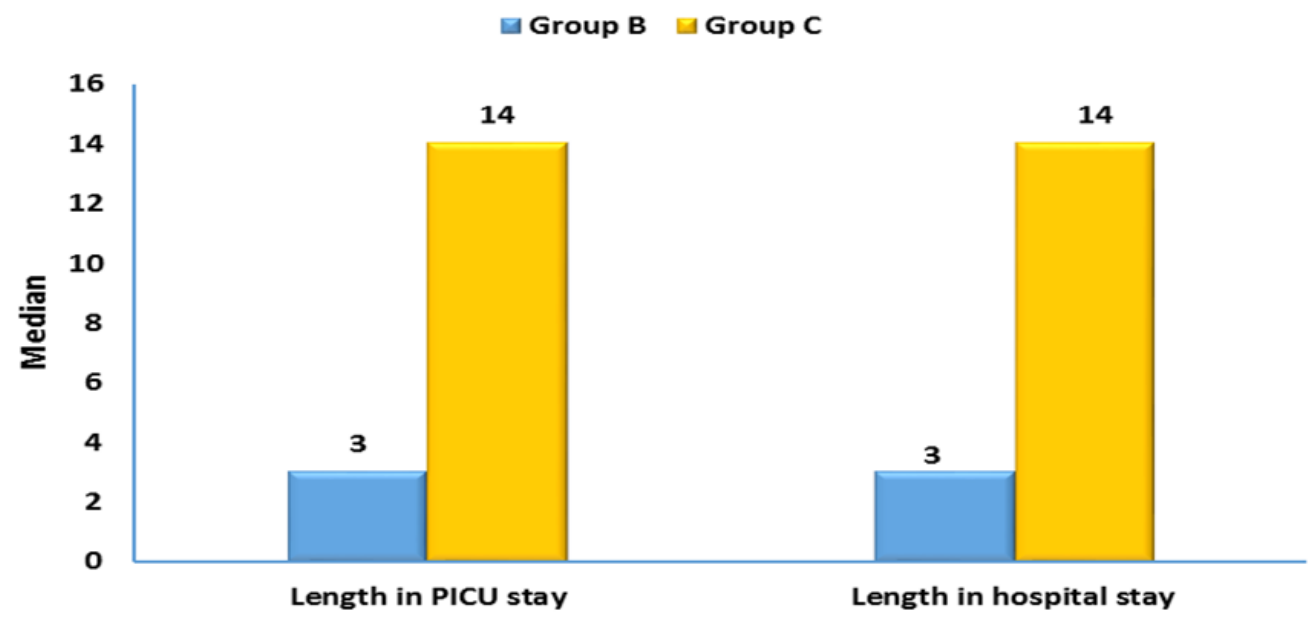

Figure (2): Means of length in PICU and Length in hospital in studied groups

Table (4) : Comparison between the studied patient groups regarding anthropometric measures :

\begin{tabular}{ccccc}
\hline & & $\begin{array}{c}\text { Group A } \\
(\mathbf{n = 2 5})\end{array}$ & $\begin{array}{c}\text { Group B } \\
(\mathbf{n = 2 5})\end{array}$ & P value \\
\hline Weight $(\mathbf{K g})$ & Median (range) & $10(9-54)$ & $14(3-33)$ & 0.043 \\
Weight centile & Median (range) & $50(3-95)$ & $50(3-96)$ & 0.968 \\
Height $(\mathbf{c m})$ & Median (range) & $72(70-120)$ & $80(43-134)$ & 0.337 \\
Height centile & Median (range) & $10(3-95)$ & $5(3-75)$ & 0.186 \\
BMI & Mean \pm SD & $21.1 \pm 7.2$ & $19.8 \pm 4.1$ & 0.422 \\
\hline
\end{tabular}

Mann Whitney U test was used for weight, weight centile, height and height centile. Independent $t$ test was used for BMI 
Table (5) : Comparison between the studied patient groups regarding TLC ، HP ، Platelets and CRP :

\begin{tabular}{lcccc}
\hline & Variable & $\begin{array}{c}\text { Group A } \\
(\mathbf{n}=\mathbf{2 5})\end{array}$ & $\begin{array}{c}\text { Group B } \\
(\mathbf{n}=\mathbf{2 5})\end{array}$ & P value \\
\hline $\mathbf{T L C}\left(* \mathbf{1 0}^{\mathbf{3}} / \mathbf{u L}\right)$ & Mean \pm SD & $26.2 \pm 9.8$ & $22.2 \pm 7.2$ & 0.107 \\
$\mathbf{H b}(\mathbf{g m} / \mathbf{d l})$ & Mean \pm SD & $8.21 \pm 3.22$ & $9.67 \pm 1.85$ & 0.057 \\
$\mathbf{P L T}\left(* \mathbf{1 0}^{\mathbf{3}} / \mathbf{u L}\right)$ & Median (range) & $215(15-460)$ & $296(150-525)$ & 0.365 \\
$\mathbf{C R P}(\mathbf{m g} / \mathbf{L})$ & Median (range) & $168(48-296)$ & $96(12-168)$ & 0.002 \\
\hline
\end{tabular}

Independent $\mathrm{t}$ test was used for TLC \& Hb. Mann Whitney U test was used for platelets \& CRP

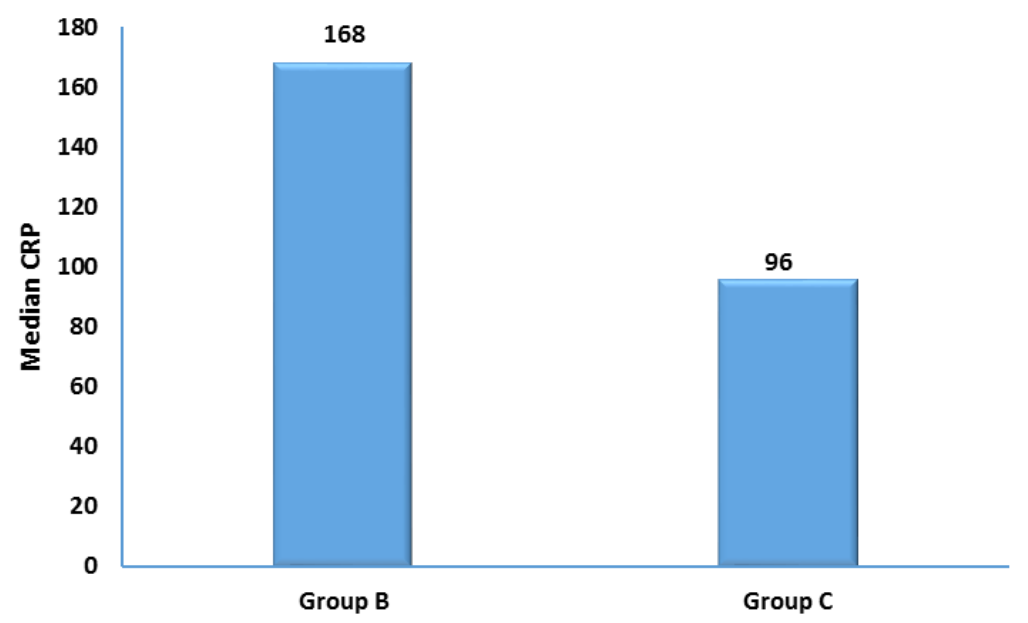

Figure (3): Means of CRP (mg/L) in studied groups

Table (6) : Comparison between the studied groups regarding some lab parameters :

\begin{tabular}{lcccc}
\hline \multicolumn{1}{c}{ Variable } & & $\begin{array}{c}\text { Group A } \\
(\mathbf{n = 2 5})\end{array}$ & $\begin{array}{c}\text { Group B } \\
(\mathbf{n}=\mathbf{2 5})\end{array}$ & P value \\
\hline S. Creatinine $\mathbf{D}_{\mathbf{1}}(\mathbf{m g} / \mathbf{d l})$ & Mean \pm SD & $3.172 \pm 0.506$ & $0.8 \pm 0.238$ & $<0.001$ \\
S. Urea $\mathbf{D}_{\mathbf{1}}(\mathbf{m g} / \mathbf{d l})$ & Median (range) & $94(35-286)$ & $21(16-30)$ & $<0.001$ \\
UOP $\mathbf{D}_{\mathbf{1}}(\mathbf{m l} / \mathbf{K g} / \mathbf{h})$ & Median (range) & $0.5(0.1-0.7)$ & $2.2(2-3.3)$ & $<0.001$ \\
GFR $\mathbf{D}_{\mathbf{1}}(\mathbf{m L} / \mathbf{m i n})$ & Median (range) & $12.5(10-42)$ & $44(31.5-156)$ & $<0.001$ \\
\hline
\end{tabular}

Independent $\mathrm{t}$ test was used for creatinine. Mann Whitney $\mathrm{U}$ test was used for urea, UOP and GFR 


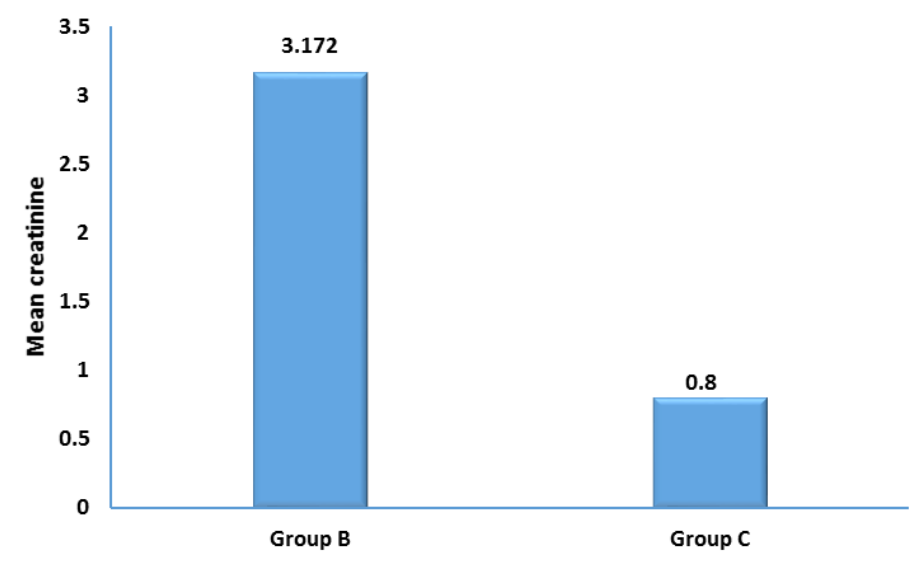

Figure (4): Means of serum Creatinine in studied groups

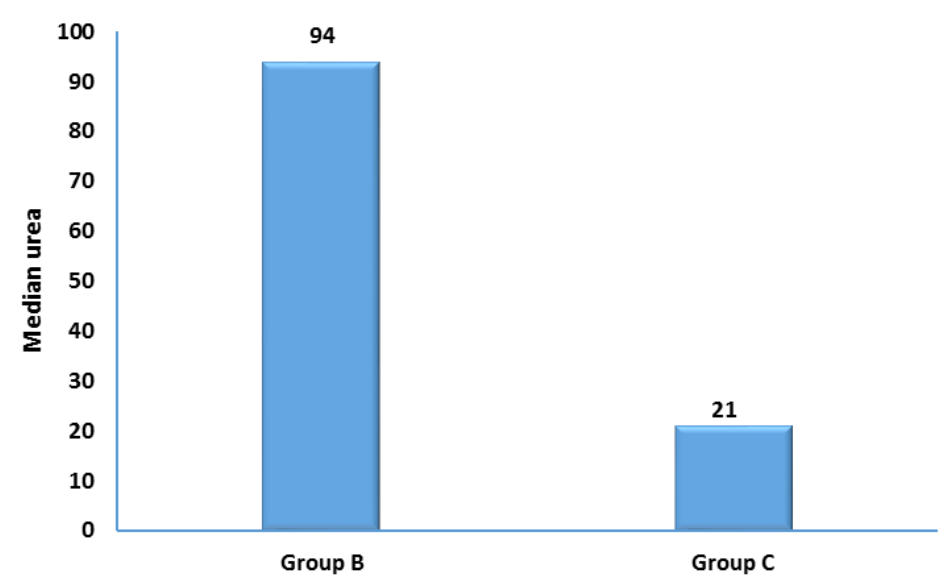

Figure (5): Means of Urea in studied groups

Table (7) : Comparison between the studied groups regarding Urine analysis :

\begin{tabular}{|c|c|c|c|c|}
\hline \multicolumn{2}{|r|}{ Variable } & \multirow{2}{*}{$\begin{array}{c}\text { Group A } \\
(\mathbf{n}=\mathbf{2 5})\end{array}$} & \multirow{2}{*}{$\begin{array}{c}\text { Group B } \\
(\mathbf{n}=\mathbf{2 5}) \\
2(8.0)\end{array}$} & \multirow{2}{*}{$\frac{\text { P value }}{<0.001}$} \\
\hline Protein & Yes $\mathrm{n}(\%)$ & & & \\
\hline Pus & $\mathrm{n}(\%)$ & $1(4.0)$ & $0(0.0)$ & 1 \\
\hline Glucose & $\mathrm{n}(\%)$ & $0(0.0)$ & $5(20.0)$ & 0.05 \\
\hline Acetone & Yes $\mathrm{n}(\%)$ & $0(0.0)$ & $5(20.0)$ & 0.05 \\
\hline Ptn/Cr ratio & Median (range) & $17.6(0-21.4)$ & - & - \\
\hline $\mathbf{K}^{+}(\mathbf{m m o l} / \mathbf{L})$ & Mean \pm SD & $6.9 \pm 0.7$ & $4 \pm 0.7$ & $<0.001$ \\
\hline
\end{tabular}

Chi-square test was used for categorical data. Independent $\mathrm{t}$ test was used for $\mathrm{k}^{+}$ 


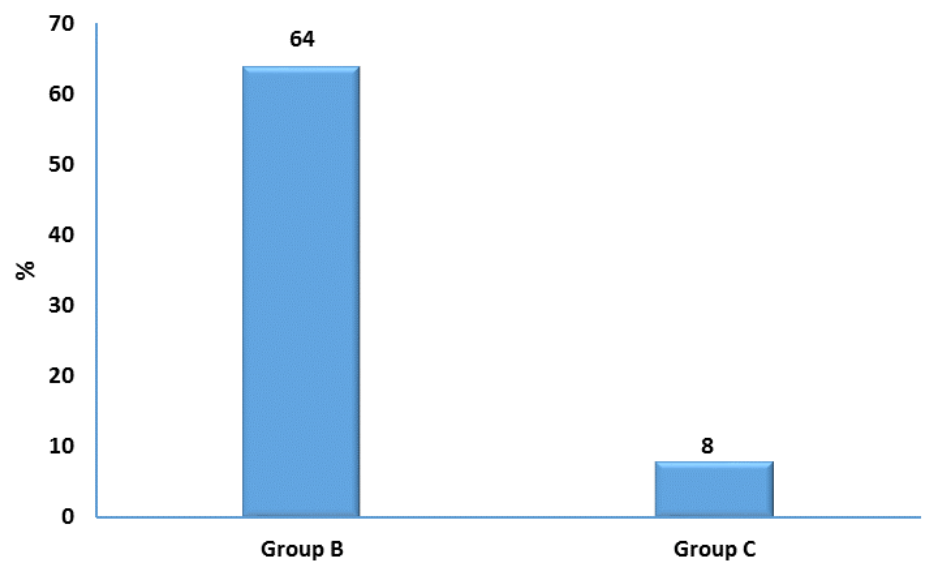

Figure (6): Means of protein in urine in studied groups

Table (8) : pRIFLE in group A :

\begin{tabular}{|c|c|c|}
\hline \multicolumn{2}{|c|}{ Variable } & n $(\%)$ \\
\hline \multirow[t]{2}{*}{ pRIFLE } & $\mathrm{F}$ & $3(12.0)$ \\
\hline & I & $22(88.0)$ \\
\hline
\end{tabular}

Table (9): Comparison between the studied groups regarding Mortality :

\begin{tabular}{cccccc}
\hline \multicolumn{2}{c}{ Variable } & & $\begin{array}{c}\text { Group A } \\
(\mathbf{n = 2 5})\end{array}$ & $\begin{array}{c}\text { Group B } \\
(\mathbf{n}=\mathbf{2 5})\end{array}$ & P value \\
\hline Mortality & Yes & $\mathrm{n}(\%)$ & $18(72.0)$ & $0(0.0)$ & $<0.001$ \\
\hline
\end{tabular}

Chi-square test was used

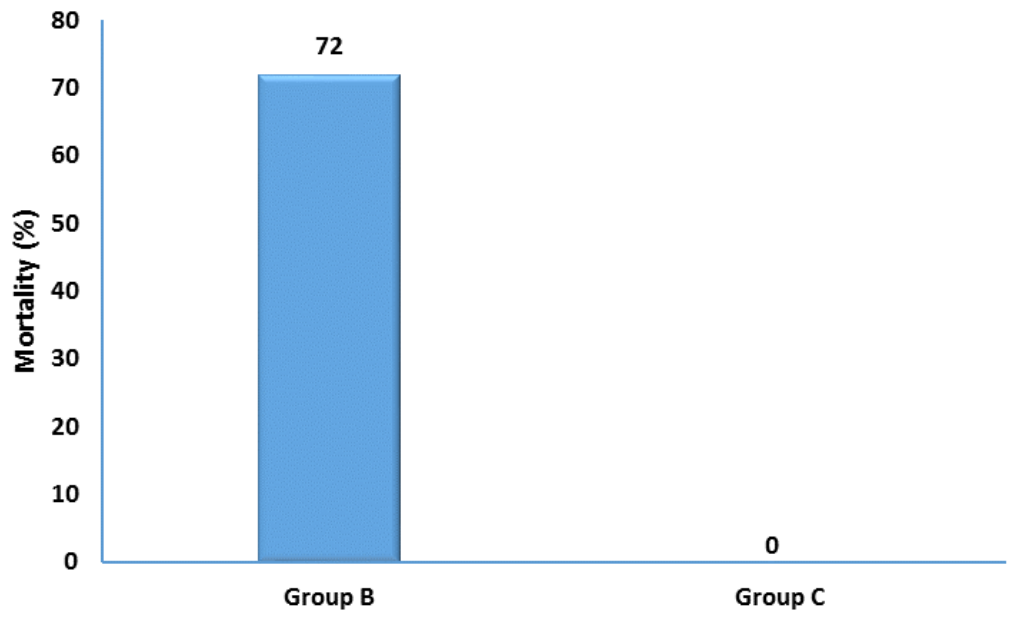

Figure (7): Means of Mortality in studied groups 
Table (10): Correlation between sTREM-1 \& other parameters in group A :

\begin{tabular}{|c|c|c|}
\hline \multirow{2}{*}{ Variable } & \multicolumn{2}{|c|}{ sTREM-1 (pg/ml) } \\
\hline & $\mathbf{r}$ & $P$ value \\
\hline Age (Years) & $-.485^{*}$ & 0.014 \\
\hline Length in PICU stay(days) & -0.327 & 0.111 \\
\hline Length in hospital stay(days) & -0.331 & 0.106 \\
\hline Weight(kg) & $-.432 *$ & 0.031 \\
\hline HT(cm) & $-.551 *$ & 0.004 \\
\hline BMI & $-.644^{*}$ & 0.001 \\
\hline $\operatorname{PLT}\left(* 10^{3} / \mathrm{uL}\right)$ & -0.179 & 0.391 \\
\hline TLC $\left(* 10^{3} / \mathrm{uL}\right)$ & -0.097 & 0.645 \\
\hline $\mathrm{Hb}(\mathrm{gm} / \mathrm{dl})$ & -0.285 & 0.168 \\
\hline Creatinine D1(mg/dl) & -0.127 & 0.545 \\
\hline $\mathbf{K}(\mathbf{m m o l} / \mathbf{L})$ & $.570^{*}$ & 0.003 \\
\hline CRP(mg/L) & 0.038 & 0.857 \\
\hline Urea D1(mg/dl) & 0.314 & 0.127 \\
\hline Protein/Cr ratio & 0.059 & 0.779 \\
\hline UOP D1(ml/Kg/h) & -0.38 & 0.061 \\
\hline GFR D1(mL/min) & -0.318 & 0.121 \\
\hline
\end{tabular}

$\mathrm{r}=$ Correlation coefficient

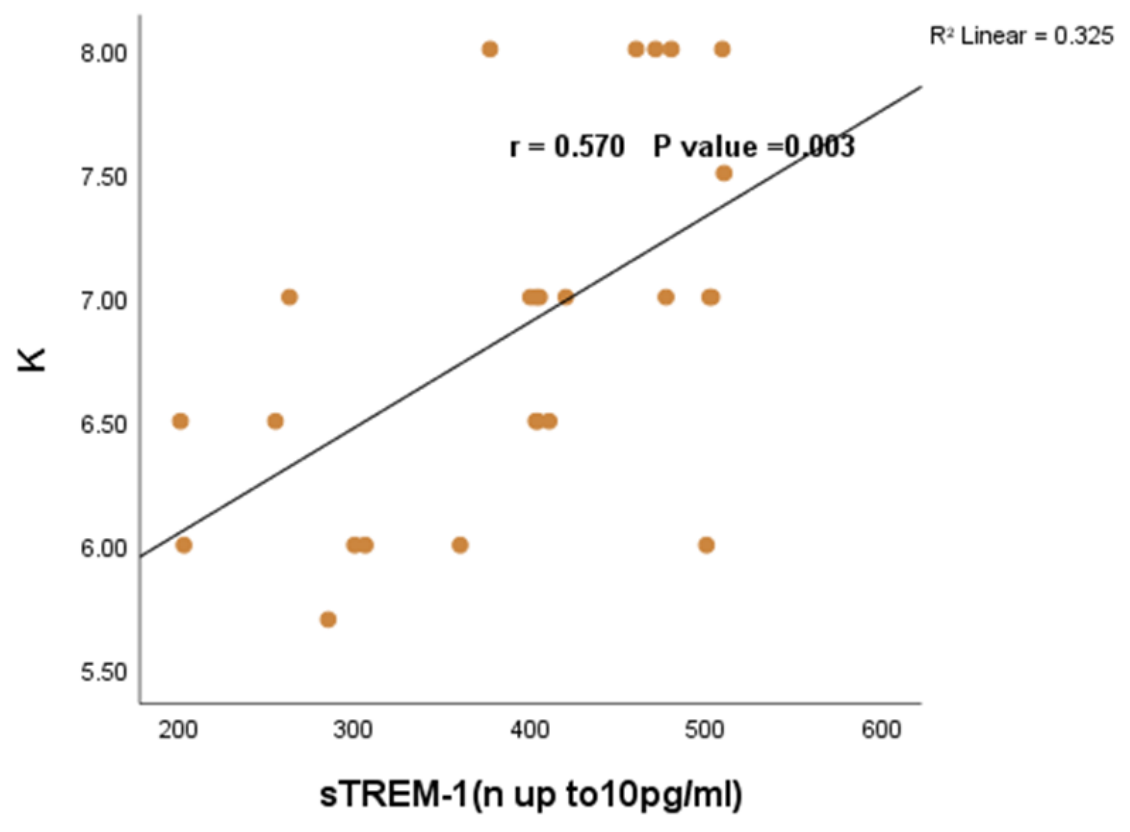

Figure (8): Means of sTREM-1 in studied groups A 
Table (11) : Correlation between sTREM-1 \& other parameters in group B :

\begin{tabular}{lcc}
\hline & \multicolumn{2}{c}{ sTREM-1 (pg/ml) } \\
Variable & $\mathbf{r}$ & p value \\
\hline Age (Years) & 0.114 & 0.587 \\
Length in PICU stay(days) & 0.185 & 0.377 \\
Length in hospital stay(days) & 0.185 & 0.377 \\
Weight(kg) & 0.054 & 0.796 \\
HT(cm) & 0.037 & 0.861 \\
BMI & -0.024 & 0.909 \\
Platelets & 0.181 & 0.387 \\
TLC(*10 $/ \mathbf{u L})$ & 0.199 & 0.341 \\
Hb(gm/dl) & -0.021 & 0.92 \\
Creatinine D1(mg/dl) & 0.352 & 0.084 \\
K(mmol/L) & 0.192 & 0.357 \\
CRP(mg/L) & 0.099 & 0.638 \\
Urea D1(mg/dl) & -0.048 & 0.82 \\
UOP D1(ml/Kg/h) & -0.123 & 0.559 \\
GFR D1(mL/min) & -0.016 & 0.939 \\
\hline
\end{tabular}

$\mathrm{r}=$ Correlation coefficient

* Significant

Table (12) : ROC analysis for sTREM-1 in prediction of sepsis related AKI :

\begin{tabular}{cc}
\hline \multicolumn{2}{c}{ ROC characteristics } \\
\hline AUC (95\% CI) & $0.955(0.907-1)$ \\
Best cutoff & $>280$ \\
Sensitivity & $84.0 \%$ \\
Specificity & $92.0 \%$ \\
P value & $<0.001$ \\
\hline
\end{tabular}

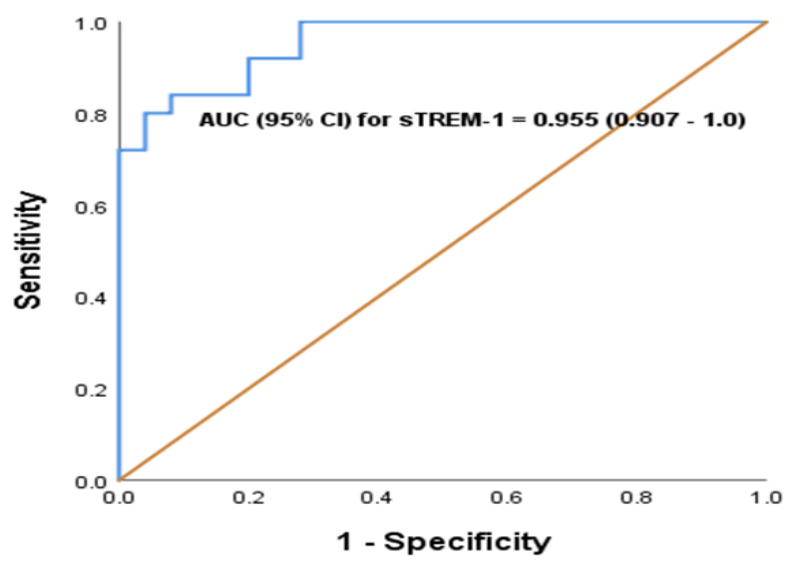

Figure (9): ROC analysis for sTREM-1 in prediction of sepsis related AKI 


\section{Discussion:}

Sepsis is a major factor contributing to PICU admissions and patient deaths. Because of its rapid progression, the disease may, within a relatively short period of time, lead to secondary multiple organ dysfunction syndrome and endanger the patient's life. AKI is well known to be associated with longer length of hospital stay, morbidity and mortality (5).

We explored the diagnostic value of a urine soluble triggering receptor expressed on myeloid cells-1 (sTREM-1) for early identification of sepsis, and the secondary acute kidney injury (AKI).

This study was conducted on 50 critically ill children with sepsis who were admitted to the PICU and 20 healthy children as control group. The children were classified as follows:

- Group (A): Sepsis patients with AKI.

- Group (B): Sepsis patients without AKI.

- Group (C): Healthy children as controls.

There were no significant differences between all the groups as regards age \& $\begin{array}{llllll}\text { gender. } \mathrm{P} & \text { values were } & 0.43 & \& & 0.709\end{array}$ respectively. This is in agreement with the study(6), which stated that statistically, no significant cross-group difference exists in terms of age, gender, serum CRP, urine output, mechanical ventilation, etiological factors, or accompanying underlying diseases. The median weight was significantly higher in group B (14 years) compared to group A (10 years). P value was 0.043 .

There were no significant differences between these groups as regards weight centile, height, height centile \& BMI. P values were $0.968,0.337,0.186 \& 0.422$ respectively.

Median length of PICU stay was significantly higher in group A (14) compared to group B (3). P value was 0.009. Median length of hospital stay was significantly higher in group A (14) compared to group B (3). P value was 0.014 . The median serum CRP was significantly higher in group A $(168 \mathrm{mg} / \mathrm{L})$ compared to group B (96 mg/L). P value was 0.002 .

There were no significant differences between the patients' groups as regards the TLC, $\mathrm{Hb}$ level and platelet count. $\mathrm{P}$ values were $0.107,0.057$ and 0.365 respectively.

The mean serum creatinine level was significantly higher in group A (3.172 $\mathrm{mg} / \mathrm{dl})$ compared to group B $(0.8 \mathrm{mg} / \mathrm{dl})$. P value was $<0.001$.The median blood urea level was significantly higher in group A (94 $\mathrm{mg} / \mathrm{dl})$ compared to group $\mathrm{B}(21 \mathrm{mg} / \mathrm{dl}) \mathrm{P}$ value was $<0.001$. 
The median blood urea level was significantly lower in group A $(0.5 \mathrm{mg} / \mathrm{dl})$ compared to group $\mathrm{B}(2.2 \mathrm{mg} / \mathrm{dl}) \mathrm{P}$ value was $<0.001$.

The median GFR was significantly lower in group A (12.5 ml/min) compared to group B (44 ml/min) $\mathrm{P}$ value was <0.001sTREM-1 showed overall significant difference between all groups ( $\mathrm{P}$ value $<0.001)$. Pairwise analysis revealed that the median sTREM-1 was significantly higher in group A (404 pg/ml) compared to group B (189.6 $\mathrm{pg} / \mathrm{ml}) \& \mathrm{C}(0 \mathrm{pg} / \mathrm{ml}) . \mathrm{P}$ value was $<0.001$. Also, it was significantly higher in group B (189.6 pg/ml) compared to group C (0 $\mathrm{pg} / \mathrm{ml})$.

Proteinuria was significantly commoner in group A (64\%) compared to group B (8\%). $\mathrm{P}$ value was $<0.001$.

Serum $\mathrm{K}^{+}$was significantly higher in group A (6.9 mmol/L) compared to group B (4 $\mathrm{mmol} / \mathrm{L})$. $\mathrm{P}$ value was $<0.001$.

There were no significant differences between the patients groups as regards the frequency of appearance of pus, glucose and acetone in urine.

As regards pRIFLE, $12 \%$ of the patients showed renal failure and $88.0 \%$ showed AKI. There was a significant positive correlation between STREM-1 \& serum $\mathrm{K}^{+}$ $(r=0.570 \& \mathrm{P}$ value was 0.003$)$.
In group $A$, there were significant negative correlations between sTREM-1 \& weight $(r=-0.432 \& P$ value $=0.031)$, height $(\mathrm{r}=-0.551 \& \mathrm{P}$ value $=0.004)$ and BMI $(r=-0.644 \& \mathrm{P}$ value $=0.001)$. There were no significant correlations between sTREM-1 \& other parameters in group B.

Our results are in contradictory to the study which (7) found that WBC count was significantly higher in the culture-proven sepsis patients than in the suspected sepsis group $(p=0.03)$. However, our results are in agreement with this study regarding the PLT count, BUN levels, and serum creatinine levels. Urine sTREM-1 levels were significantly higher in the culture-proven group compared with the suspected sepsis group $(\mathrm{p}<0.001)$. No correlation was found between baseline sTREM-1 and CRP levels $(\mathrm{r}=0.14, \mathrm{p}=0.25)$.

ROC analysis was done for urine sTREM-1 levels ability to detect sepsis related AKI. It showed significant AUC of 0.955 with $95 \%$ confidence interval ranging from 0.907 to 1.0 . The best cutoff point was $>280 \mathrm{pg} / \mathrm{ml}$ at which sensitivity \& specificity were $84 \%$ \& $92 \%$ respectively. $\mathrm{P}$ value was $<0.001$.

Our results are in agreement with that study (7) which performed a multi-regression analysis to evaluate the ability of urine sTREM-1 levels for predicting the prognosis in neonates with sepsis. They found that 
urine sTREM-1 levels were an independent factor for predicting culture-positive sepsis $(\mathrm{p}<0.001)$. They performed a ROC analysis for urine sTREM-1 levels. The AUC was 0.87 for urine sTREM-1 levels. Using a cutoff point for a urine sTREM-1 level of $78.5 \mathrm{pg} / \mathrm{ml}$, the sensitivity was $0.90 \%$, the specificity was $0.78 \%$, the positive predictive value was 0.68 , and the negative predictive value was 0.94 .

\section{Conclusions:}

Urine sTREM-1 may play a role in the early diagnosis of sepsis. Also, urine sTREM-1 has significance in the early diagnosis of sepsisrelated AKI, and could likely become a new marker for such conditions. Prospective clinical studies are still wanted to provide further proof for the clinical diagnostic value of urine sTREM-1in sepsis. In addition, further studies are expected on the role and mechanisms of urine sTREM-1 in AKI.

\section{References:}

1- Post EH, Su F, Hosokawa K, Taccone FS, Herpain A, Creteur J, et al.: Changes in kidney perfusion and renal cortex metabolism in septic shock: an experimental study. J Surg Res 2017; 207:145-154.

2- Linder A, Fjell C, Levin A, Walley KR, Russell JA, Boyd JH. Small acute increases in serum creatinine are associated with decreased long term survival in the critically ill. Am J Respir Crit Care
Med. 2014;189(9):1075-1081.

doi: 10.1164/rccm.201311-2097OC.

3- Otero RM, Nguyen HB, Huang DT, Gaieski DF, Goyal M, Gunnerson KJ, et al. Early goal-directed therapy in severe sepsis and septic shock revisited: concepts, controversies, and contemporary findings. Chest 2006; 130:1579-1595.

4- Liu XR, Xu J, Wang YM, Ji MS, Liu FS. The effects of paeoniflorin injection on soluble triggering receptor expressed on myeloid-1 (sTREM-1) levels in severe septic rats. Korean J Physiol Pharmacol 2016; 20:565.

5- Vincent JL, Nelson DR, Williams MD.(2011) Is worsening multiple organ failure the cause of death in patients with severe sepsis? Crit Care Med. 2011;39:1050-1055. doi: 10.1097/CCM.0b013e31820eda29.

6- Long-xiang Su, Lin Feng, Jie Zhang, Yong-jiu Xiao , Yan-hong Jia , Peng Yan , Et al. (2011). Diagnostic value of urine sTREM-1 for sepsis and relevant acute kidney injuries: a prospective study. Crit Care. 2011; 15(5): R250.Published online 2011 Oct 24. doi: $10.1186 / \mathrm{cc} 10508$.

7- Senem Alkan Ozdemir, Esra Arun Ozer, Ozkan Ilhan, Sumer Sutcuoglu and Mansur Tatl.(2018). Diagnostic value of urine soluble triggering receptor expressed on myeloid cells (sTREM-1) for late-onset neonatal sepsis in infected preterm neonates. Journal of International Medical Research 2018, Vol. 46(4) 1606-1616 ! The Author(s) 2018 Reprints and permissions: sagepub.co.uk/journalsPermissions.nav DOI:

10.1177/0300060517749131journals.sagepub.com/ho me/imr .

To cite this article: Mohamed A. Elbaz, Effat H. Assar, Heba M. Sarhan, Ayat I. Fattouh. The Value of Urine Soluble Triggering Receptor Expressed on Myloid Cell-1 in Early Diagnosis of Sepsis Associated Acute Kidney Injury. BMFJ 2021;38(1): 380-394. DOI: 10.21608/bmfj.2021.56361.1367 